\title{
NURSSING PRACTICES
}

Nabilah Siregar
Braw ijaya University, Indonesia
Korespondensi: Nabilah Siregar
Email: nabilahsiregar92@gmail.com
$\begin{array}{ll}\text { Info } & \\ \text { Artikel } & : \\ \text { Online } & : \text { http://journal.umy.ac.id/index.php/ijnp } \\ \text { ISSN } & : 2548 \text { 4249 (Print) } \\ & : 2548592 X \text { (Online) } \\ \text { DOI } & : 10.18196 / \text { jinp.2283 }\end{array}$

\section{Pedriatric Population in Disaster: How Should We Care for Them?}

\begin{abstract}
Background: Disaster might cause many impacts for vulnerable people, especially children (pediatric population).

Objective: This paper aims to explain how should nurse do in caring for children in disaster management.

Method: This review is conducted by searching many literatures from Science direct, ProQuest, PubMed, and google scholar about children and care for pediatric population.

Result: Management for children in disaster should consider to many important things, such as: physical condition, psychology, development and behavior. Health practitioner include nurse should care for and involve families, consider to physical and psychological need and protect children from exploitation or any harms to prevent Post Traumatic Distress Syndrome (PTSD) in disaster management. Nurse should pay more attention for children as a unique vulnerable population by considering all aspects of pediatric and involve their families in disaster management.
\end{abstract}

Keywords: Pediatric, Disaster, Care

\section{INTRODUCTION}

Morbidity and mortality rate in the world al ways increase due to many emergency cases that occurred in hospital or pre hospital setting, include disaster. Disaster as an event that caused of natural or social factors, might cause many negative effects such as economical aspect, health disorder and many victims include children or pediatric population. In the world, about $50 \%$ of all disaster victims are children (Cooper et.al., 2014). Meanwhile, Indonesia is also a country that has a high risk to get many kind of natural disasters, because Indonesia located in Pacific ring of fire. Many health problems could occur as impact of disaster like Tsunami, or Vulcano eruption that occurred recently and cause respiratory problem such as acute respiratory tract infection (Puspnegoro \& Sujudi, 2016).

Infant and children are vulnerable population because of many reasons include less of preparedness of health practitioners especially to treat or care for them during disaster (Drayna et.al., 2012). In United States, $25 \%$ children under 18 years old were disaster victims. So, pediatric population should get special attention, because of many factors, such as: physiologic, development, behavior, and mental health of children, especially in disaster preparedness planning (Blake \& Blowers, 2018).

Health practitioners should remember that children have not ability to save themselves during disaster because of unability in motoric and cognitive to make a decision for their lives (Emergency Medical Service for Children, 2016). In pre hospital setting, children's needs are depend on their parents. In almost cases, children who were separated from their parents would have mentally disorder. So health practitioners include nurse should involve their parents and care for them based on nursing care guideline, not only in pre hospital but also in hospital setting to fulfill their needs. They also 


\section{NONRESANOUNNANG \\ PRACTICES}

should give rapid response to disaster. Consider to many pediatric population as disastervictims, hospital also plays important roles based on hospital disaster plan to treat the children (National Association Pediatric of Nurse Practitioners, 2011).

Many pediatric population in disaster victims might not get appropriate care, so morbidity and mortality rates could increase. One of the factors that could affect it is less of nursing care preparedness to the children. Those are basic and be reason for author to explore and describe aspects about caring for them. This review is conducted to explain how should nurse do in caring for children in disaster management.

\section{METHODS}

This literature review is conducted by searching many literatures from Science direct, ProQuest, PubMed, and google scholar about children and care for pediatric population. Criteria for the literatures are 1) Explain related to the topic about pediatric care in disaster management, 2) Articles exist in 10 years recently (2008-2018). The process of searching was conducted on June to July 2018, by using keywords: pediatric in disaster, children in disaster, pediatric care in nursing disaster management, pre hospital care for children in disaster, and in-hospital care for children in disaster. Finally, 11 review articles and one book were used in this review. The process of searching literature is described by using Prisma Chart on chart

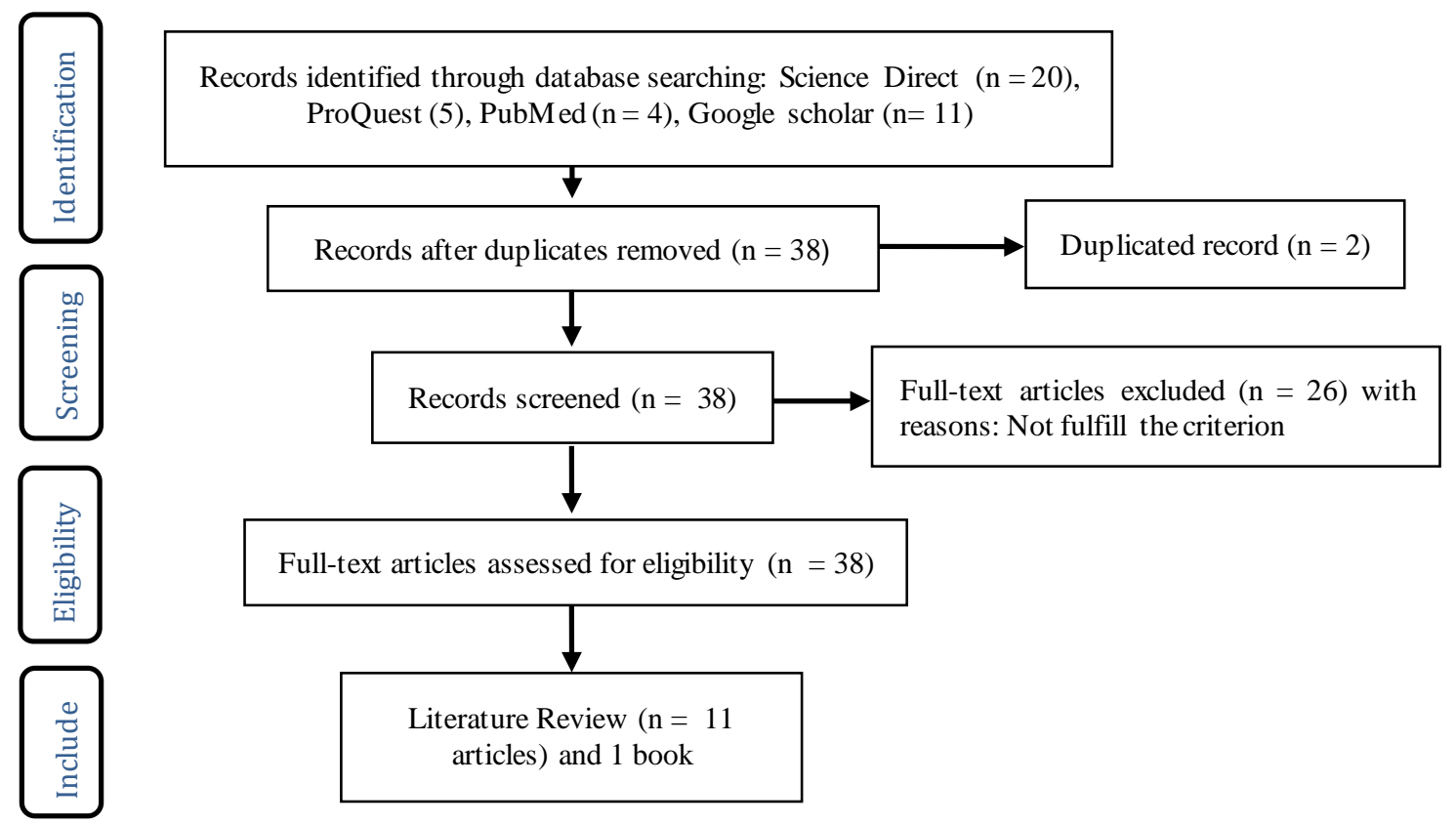

Chart 1. Flow chart of literature searching and selection

\section{RESULTS AND DISCUSSION}

The results of searching about fourty articles about pediatric care in disaster management were found, but only 11 review articles and one book from Science Direct, PubMed, and google scholar are used in this review after screening, eligibility and include processing.

Many disasters in the world have caused many pediatric victims. In 2005, Hurricane Katrina had caused victims with pediatric as the most population among disaster victims include newborn. A hospital near the disaster site received and stabilized 122 infants (Orlando,et.al., 2010). Not only that, Indonesia also is one of many countries with high risk to have many disasters have caused many pediatric victims. Because of Indonesia located in Ring of Fire lane so makes many natural disasters could occur, like Tsunami, Eruption, and other disasters. In 2013, Eruption of Sinabung mountain in North Sumatera occurred and caused 2,856 
children with all education levels (elementary, junior and senior high school) were evacuated (Nugroho, 2013). Most of evacuees include children had various health problems such as: Acute Respiratory Tract Infection (39.1\%), Gastritis (16\%), Conjungtivitis (12.4\%), diarrhea (4.9\%), and skin diseases (0.7\%) (Pakpahan, 2016).

Weiner (2009) said that the proportion and severity of illness or injury in pediatric victims are dependent on location, time and type of disaster. They are more likely be victims when they are on the site of disaster like school hostage or bombing in school area or daycare center. Disaster that occures in school time for children to study also results more proportion of them as victims. Type of disaster like tsunami in 2004 in Indian ocean results more victims of pediatric population than Hurricane in Katrina because the power of ocean wave to sweep away them include health practitioners. In other hand, the re were still many health practitioners to help children as victim of this type of disaster. Most of children have less ability to escape and protect themselves.

National Association of Pediatric Nurse Practitioners (2011) explained that pediatric population is one of many vulnerable populations because they live dependently to their parents, not only physic but also psychologic. They also have not had physical capacities and ability in taking decision to save and protect themselves. Moreover, health practitioner should consider to charachteristic of children such as: Physiology anatomy (small body size and fewer body fat, fewer blood volume, thinner skin, and lower immune system), physical and emotional dependent, and development (Drayna et.al., 2012). Rapid minute volume, large and permeable body skin make them susceptible to be exposured and get debris or other negative effects from biological, toxic or chemical materials (American Academy of Pediatrics, 2015).

In addition, children would have many problems during or post disaster. During disaster, care providers should pay more attention about shelter, diapers, formula, foods or other supplies that appropriate to their age. Their immune systems are lower than adults because children especially infants and children under five years have not perfect or mature immunity. Some of them might not get complete immunization also. So, children are more likely to get infection from disaster, like outbreak or hazardous environments. Children tend to get malnutrition easier in pre, during, and post disaster phase, dehydration, and multiple injury easier than adults (Weiner, 2009). Children also might need medication with age-appropriate dosage, health equipments, and care delivery more intensive than adults. After disaster, chidren would have other problems that are long-terms effects of disaster such as post traumatic stress disorder or behavioral problems. Because of those conditions and reunification as an issue in disaster, so emergency practitioners should coordinate and strive to take them back to their parents or guardians as soon as possible (Cornette \& So, 2011).

Considering to children' characteristics, health practitioners should have knowledge and skill about caring for pediatric population in disaster, whether in pre hospital or in-hospital setting, and use health equipments and medication appropriately (Bouton \& Becker, 2016). World Health Organization and International Coun cil of Nursing (2009) said that Nurses' competencies in caring for vulnerable people include pediatric population are: a) Identify vulnerable group, their responses and needs; b) Create environment that help them to live with their functions as possible as they can; c) Advocate vulnerable population; d) Identify resources to help them; e) Caring for vulnerable population (pediatric); f) Collaborate with other health organization to help complete vulnerable people needs (children' needs).

Health providers especially nurse have important rule to treat them, care and help to address needs and save children, especially pay a special attention in their physical, mentally or psychological needs. So. When caring for pediatric population in disaster, nurse should: a) Understand about emergency planning in caring during disaster; b) Use and supply medical equipments according to the age and body size; c) Understand about medication using based on dosage for children; d) Do triage for childre $n$ and their families; e) Do physical and psychological 


\section{NUTRSING \\ PRACTICES}

care; f) Provide stabil and safety environment for children and their families in recovery phase; $g$ ) Collaborate with other professional health team to construct infrastructure in community and support for long term care based on childrens' needs (National Association of Pediatric Nurse Practitioners, 2011).

Pediatric also could get exploitation or sexual abuse by adults, so they would get Post Traumatic Distress Syndrome (PTSD) (Bouton \& Becker, 2016). Kar (2009) also said that PTSD occurred about $5-43 \%$ in pediatric population after disaster. Children especially pre school children usually get anxiety. So, rapid initial screening about syndrome and psychologic in children or their parents is needed. Interve ntion that health practitioners include nurse could do when caring pediatric population in disaster are: a) Communicate and support children, and apply family context approach in order to understand their conditions; b) Psychotherapy could be applied by playing or art activities, and give a chance for them to tell something or someone that they love; c) Post disaster Consultation to help communication between children and their families or society; d) Cognitive Behavior Therapy, to children or teenagers; e) Emotional first aid technique to clarify the facts, to normalize childrens' reactions, and to teach about problem solving; f) Group therapy; g) Playing therapy like story telling and drawing; $h$ ) Involve childrens' parents or families (psychoeducation); i) Refer patients orvictims to secondary health care; and j) Medication using like antidepressant for victim with convulsive or other serious conditions.

In addition, health providers include nurse should have a good disaster plan and preparedness to address many problems that might be occurred in children. Comprehensive disaster plan not only in pre hospital (site or community) but also inhospital are needed to give immediate and appropriate response as disaster management. Organized plan and system with trained pediatric health providers and pediatric nurses, and health related technologies should be prepared before disaster occurred for better pediatric disaster management. Pre hospital and hospital reponse could be correlated. Pediatric victims must be transferred to hospitals that have complete and good equipment and staff for pediatric care (Weiner, 2009). Because of distinctive physical, development, and psychological aspects of children, it is important to have disaster plan for pediatric population (Burke et.al., 2010).

Furthermore, Drayna et.al., (2012) and New York City Health (2008) described manythings that should be considered in caring for pediatric victims in hospital based on Hospital Guideline for Pediatric Preparedness: a) Activate the hospital disaster plan; b) Do appropriate pediatric triage: JumpSTART algorithm on disaster site, a rapid visual assessment and more detailed triage assessment in hospital, include mentally status assessment based on their developments; c) Decontamination according to pediatric age groups, and caregiver should use personal protective equipment; d) Provide adequate nutrition based on age and condition of children; e) Hospital should prepare surgeon and surgery related equipment with appropriate size, and patient bed at Intensive Care Unit and Surgery room; f) It is recommended to hospital to build an Information and Family support Center in disaster plan to address psychosocial problem and give family-centered pediatric care; g) Prevent or control infection between infected children and their caregivers; h) Supply medications to children with emergency condition, sufficient and use exact dosage for children; i) Care for physical need but also mental or psychosocial in children and their caregivers pre, during, and post disaster; j) Save children from kidnapping or any harm, transport victim inter and intra hospital to appropriate room and supported by staff and equipments; k) Staff or care giver, doctor and nurse identification and development, with experience and skill in pediatric care; and I) Conduct training for caregiver about trauma life support and emergency care in children.

Moreover, Orlando et.al. (2010) explained that Pediatric nursing care in hospital according to disaster management phases are: a) Mitigation: Nurses play important roles such as identify safe location or evacuation, design and planning for 
care unit like perinatal or pediatric unit; b) Preparedness: Nurses'roles in this phase are to be involved in personal development of disaster plan, identify option of caring by family, self preparedness by education and training to give high standard care as what victims need; c) Response: Nurses have roles to assess, triage, physical and mental monitoring to patient (victim) that still survive, give appropriate care, evacuation children, infant and their mothers, communicate and transfer or discharge patient appropriately; and d) Recovery: Nurses with hospital party to anticipate emergency medical care for routin care to children and their mothers in community, coordination and collaborate with health care in community about shelter, food supply; and mental care of children and their families.

Blake and Bowers (2018) also said that considered to unique needs in pediatric population or adolescents such as physical, psychological, development and behavior require health practitioner include nurse to pay particular attention fo them in disaster and emergency preparedness planning. Unfortunately, a study in 2015 said that only $47 \%$ of all hospitals had disaster plan for pediatric population. Not only hospital near the disaster site, but stakeholders in community have to prepare such a system-based approach by coordinating with other community partners. Country with stakeholders, Departement of Health, emergency medical service, hospital whether pediatric hospital or other hospitals, pediatric experts and surge capacity involved and work together in disaster management or preparedness plan. Emergency or Disaster preparedness and response plan for pediatric should be applied sustainably and integrated with all local or regional health care systems. A special guideline or standard and training for addressing pediatric needs is required in comprehensive disaster plan. Even in this crises situation, registered or advanced pediatric nurse must be involved and play important roles in disaster plan and preparedness. Pediatric nurse should understand all about children, work together, provide communication and coordination with other local community health care or providers, school, church or other worship places to strengthen disaster preparedness. Pediatric nurses also play a role as advocator for pediatric victims by motivating or ensuring policymaker about how crucial a legislation for pediatric in disaster is. Health policy regarding to unique characteristic and long-term impact of disaster to all aspects of children is needed to help providers to recognize and address their needs.

Furthermore, caring for vulnerable population include children has a main goal to make them less of vulnerable, be safe and resilient. To achieve this goal, National Commission on Children and Disaster (2010) made 11 categories as Recommendation to achieve the goal and improve preparedness, response and recovery for pediatric in disaster. Those categories are: a) Integration, means disaster management activities especiallymeet pediatric's needs should integrated with inter and intra governmental; b) Mental Health, means integrate activities in care for mental and behavioral health of children with trained or expert psychological or mental professionals, public health or other related professionals whether in preparedness and post disaster. The activities like training program or counseling;c) Child Physical Health and Trauma, are health care consider to pediatric medical $n$ appropriate dosage and administration, conducted by clinical trained health profesionals about pediatric care, formal pediatric care system should be established in regional country to support pediatric surge, critical or intensive care for children. Mental health support is also needed to recover and support restorating of children; d) Emergency Medical Service and Pediatric Transport, describe that Emergency Medical Service in regional or country is required to improve the capability to transport and treat children during pre hospital setting, and emergency transport should be sufficient; e) Disaster Case Management, means that holistic service with standard and appropriate resources are required in disaster case management to address the needs of children and their families; f) Child Care and Early Education, this recommendation said that disaster preparedness and plan should be improved in caring for children, planning of evacuation, relocation, shelter, and reunification between children and their families should be prepared promptly; g) Elementary and Secondary Education, are needed to support collaboration and coordination with 


\section{NUNRSEINSING \\ PRACTICES}

emergency providers, so teachers should be certified in this area and situation; h) Child Welfare and Juvenile Justice, that welfare and justice agencies are needed to support preparedness and recovery rapidly and mini mize the impact of disaster to children; i) Sheltering include service and supplies; j) Housing; and k) Evacuation, include reunification between children and their families after disaster (Wizemann et.al., 2014).

\section{CONCLUSIONS}

Health practitioners especially nurse should pay more attention for children as a unique vulnerable population, and consider all aspects of them in disaster management. Physical, pshycological, development, behavior and also their families should be considered by nurse in caring for them. Not only addressing pediatrics need, but nurse also playing a role to advocate them to policymakers about providing special standard or regulation for pediatric in disaster. Nurse worked in taking care children with local government, department of health and other related-parties in community.

\section{REFERENCES}

American Academy of Pediatrics. (2015). Ensuring the health of children in disasters. Pediatrics, 136(5). doi: 10.1542/peds.2015-3112

Blake, N., \& Bowers, E.K.F. (2018). Disaster preparedness: Meeting the needs of children. Journal of Pediatric Health Care, 32(2), 207-210. doi: 10.1016/j.pedhc.2017.12.003.

Bouten, M., \& Becker, B.M. (2016). Children and disaster. Ciottene's Disaster Medication (Second Edition) (pp. 53-59).

Burke, R.V., Iverson, E., Goodhue, C.J., Neches, R., \& Upperman, J.S. (2010). Disaster and mass casualty events in the pediatric population. Seminars in pediatric Surgery, 19, 265-270. doi: 10.1053/j.sempedsurg.2010.06.003
Cooper, L., Guan, H., Hernandez, A.A..O., Gallardo, B.L., Rivera, G., Wathen, G., Shulman, B., \& Berman, S. . (2014). Pediatrics in disasters evaluation of a global training program. Advances in Pediatrics. doi: 10.1016/j.yapd.2014.03.003.

Cornette, E.C. \& So, A.P. (2011). Children and disaster planning: The national commission on children and disaster's findings and recommendations. Journal of Emergency Management, 9(2). doi: 10.5055/jem.2011.0049.

Drayna, P.C., Hansen, A., Boggs, R., \& Locklair, M.R. (2012). Disaster management and emergency preparedness for children and youth with special health care needs. Division of Pediatric Emergency Medication, 13(2).

Emergency Medical Service for Children. (2016). Addressing the needs of children in disaster preparedness exercises 2nd edition. Retrieved from www.stritch.luc.edu/emsc.

Kar, N. (2009). Psychological impact of disasters on children: Review of assessment and interventions. World Journal of Pediatrics, 5(1). doi: 10.1007/s12519009-0001-x.

National Association of Pediatric Nurse. (2011). Pediatric nurse practitioners role in disasters involving children. Journal of Pediatric Health Care, 25(4), 9A-10A. doi: 10.1016/j.pedhc.2011.03.004.

New York City Health. (2008). Children in Disasters: Hospital guidelines for pediatric preparedness. The Centers of Bioterrorism Preparedness Planning Pediatric Task Force ( $3^{\text {rd }}$ Ed.)

Nugroho, S.P. (2013). 2.586 Anak pengungsi Sinabung tetap bersekolah. Retrieved from https://www.bnpb.go.id/2-856anak-pengungsi-sinabung-tetapbersekolah. 
Orlando, S., Danna, D., Giarratano, G., Prepas, R., \& Johnson, C.B. (2010). Perinatal considerations in the hospital disaster management process. JOGNN, 39(4), 468$479 . \quad$ doi: $10.1111 / \mathrm{j} .1552-$ 6909.2010.01158.x.

Pakpahan, Lisbeth. (2016). Kesiapan Manajemen Rumah Sakit Umum Kabanjahe dalam Penanganan Korban Bencana Erupsi Gunung Sinabung di Kabupaten Karo Provinsi Sumatera Utara Tahun 2013. Repository institusi Universitas Sumatera Utara. Retrived from http://repository.usu.ac.id/handle/12345 6789/61723.

Pusponegoro, A.D., \& Sujudi, A. (2016). Kegawatdaruratan dan bencana: Solusi dan petunjuk teknis penanggulangan medik dan kesehatan. Jakarta Timur: PT. Rayana Komunikasindo.

Weiner, D.L. (2009). Lessons learned from disaster affecting children. 10(3).

Wizemann, T., Reeve, M., \& Altevogt, B. (2014). Preparedness, Response, and Recovery Considerations for Children and Families: Workshop summary. United States: The National Academics Press.

World Health Organization and International Council of Nursing. (2009). ICN Framework of Disaster Nursing Competencies. 